\title{
Analisis Sistem Informasi Kesehatan Daerah (Sikda) Generik Di Unit Rekam Medis Puskesmas Langsat Tahun 2020
}

\author{
Welly Sando*1, Muhammad Dedi Widodo ${ }^{2}$, Suci Badri Yana ${ }^{3}$ \\ Program Studi S1 Kesehatan Masyarakat STIKes Hang Tuah Pekanbaru, Indonesia \\ Jalan Mustafa Sari No 5 Tangkerang Selatan Bukit Raya Pekanbaru, Riau \\ *Correspondence Email : Welly.agir81@gmail.com
}

\begin{abstract}
Regional information system is a term that is used to describe a system consisting of a combination of input such as human resources (brainware), software, information needs format (informware), information technology and communication technology, the process of sending an analysis report recording (entry). the feedback and output data information mechanism that can be accessed together and has adequate quality, regional information system in the Langsat Health Center Medical Record Unit only started in 2017, SIKDA in the medical records unit lacks Human Resources because it does not there is a Medical Record and IT graduate. Obstacles that occur, such as disruption of soft ware and hard ware networks when opened, experience delays, causing delays in the given services. For the Fund itself, there is no special budget provided for the implementation of theregional information system application because it has been allocated by the Health Office. Budget allocation of funds is held only if needed. This type of qualitative research uses interview and observational sheets. The research was conducted in February-September, at Langsat Public Health Center, Pekanbaru City. The research subjects were the Head of Langsat Community Health Center, the Head of the Medical Records Unit, the person in charge of SIKDA, and Operators. Data analysis was used by systematically managing the interview guidelines, then processing the data, data from observations were identified to describe each variable, a summary will be presented in a narrative form. The results of this study indicate that the Generic regional information system in the Medical Records Unit has been running at its maximum, even though there is a lack of calm in Human Resources there are no medical records and IT graduates. Infrastructure is lacking in terms of ginset, Fund Allocation is not a special budget. Must improve Human Resources, Facilities and Infrastructure.
\end{abstract}

Keywords: Health Centre, Medical Records, SIKDA.

\begin{abstract}
ABSTRAK
SIKDA adalah sebuah istilah yang digunakan untuk mengambarkan suatu sistem yang terdiri dari gabungan antara inpu seperti SDM (brainware), perangkat lunak (software),format kebutuhan informasi (informware), teknologi informasi dan teknologi komunikasi, proses pengiriman laporan perekam (entry) pengelolah analisa mekanisme feedback dan output data informasi yang dapat diakses bersama-sama dan memiliki kualitas yang memadai, SIKDA di Unit Rekam Medis Puskesmas Langsat baru berjalan pada Tahun 2017, SIKDA di unit Rekam medis kekurangan Sumber Daya Manusia kerna tidak adanya tamatan Rekam Medis dan IT. Kendala yang di dapat seperti terjadinya gangguan jaringan soft ware dan hard Ware jika dibuka menggalami kelambata membuat keterlambatan dalam Pelayanan yang di berika. Untuk Dana sediri tidak ada anggaran kusus yang disediakan untuk Pelaksanaan aplikasi SIKDA karena sudah dialokasi oleh Dinas Kesehatan Anggaran alokasi dana di adakan jika di butuhkan saja, Jenis penelitian kualitatif dengan menggunakan lembar wawancara dan observasional. Waktu penelitian dilakukan pada bulan februari-Sebtember, di Puskesmas Langsat Kota Pekanbaru. Subjek penelitian yaitu Kepala Puskesmas Langsat, Kepala Unit Rekam Medis, Penaggung jawab SIKDA, dan Operator. Analisis data yang digunakan dengan cara mengatusecara sistematis pedoman wawancara,data, data dari observasi diidentifikasi untuk menggambarkan masing-masing variabel, ringkasan akan disajikan dalam bentuk narasi. Hasil penelitian ini menunjukkan SIKDA Generik di Unit Rekam Medis sudah berjalan dengan maksima walau kurangnya
\end{abstract}

Received: 29 October 2020, Accepted : October 2020 - Jurnal Photon Vol.11 No.1

DOI : https://doi.org/10.37859/jp.v11i1.2237

PHOTON is licensed under a Creative Commons Attribution-ShareAlike 4.0 International License 
tenanga Sumber Daya Manusia tidak ada tamatan Rekam Medis dan IT. Sarana Prasarana kurang dari segi ginset, Alokasi Dana tidak adanya anggaran kusus. Harus menigkatkan Sumber Daya Manusia, Sarana dan Prasarana.

Kata Kunci : Puskesmas, Rekam Medis, SIKDA

\section{Introduction}

Pada tahun 2002 menteri kesehatan mengelukan keputusan mentri kesehatan no.511 tentang kebijakan dan strategi sistem Informasi Kesehatan Nasional (SIKNAS) yaitu adalah sistem informasi yang berhubung dengan sistem-sistem informasi baik secara nasional maupun internasional dalam rangka kerjasama yang saling mengunungkan.dan Kepmenkes No.932 tentang petunjuk pelaksanaan pengembangan Sitem Informasi Daerah (SIKDA) di kabupaten/kota adalah sebagai bagian sub sistem SIKDA yang ada di provinsi,sedangkan SIKDA yang ada di provinsi adalah bagian sub sistem Informasi Kesehatan Nasional (SIKNAS),namun dengan terjadinya desentralisasi sektor kesehatan ternyata mempunyai dampak negatif. Terjadinya kemunduran dalam pelaksanaan sistem informasi kesehatan secara nasional. Kementrian Kesehatan mengembangkan aplikasi Sistem Kesehatan Daerah (SIKDA) Generik sebagai sarana untuk mengumpulkan data hasil kegiatan puskesmas dalam rangka mendukung indikator rencana strategis Kementerian Kesehatan Tahun 2015-2019 di bidang pengembangan SIK. Sistem Informasi Kesehatan Daerah (SIKDA) adalah sebuah isitilah yang digunakan untuk mengambarkan suatu sistem yang terdiri dari gabungan antara inpu seperti SDM (brainware), perangkat lunak (software),format kebutuhan informasi (informware), teknologi informasi dan teknologi komunikasi,proses pengiriman laporan perekam (entry) pengelolah analisa mekanisme feedback dan output data informasi yang dapat diakses bersama-sama dan memiliki kualitas yang memadai (DepKes,2014), SIKDA Generik juga merupakan salah satu upaya Kementrian Kesehatan dalam menerapkan standarisasi Sistem Informasi Kesehatan dalam menerapkan standarisasi Sistem Informasi Kesehatan sehingga dapat tersedia data dan informasi kesehatan yang akurat,tepat dan cepat dalam menambil kebijakan di bidang kesehatan baik di tingkat pusat maupun di daerah dengan mendaya gunakan teknologi informasi dan komunikasi (TIK).

Perkembangan Teknologi Informasi dan Komunikasi (TIK) yang pesat memberikan kemudahan dalam penguatan dan pengembangan Sistem Informasi Kesehatan. Dan saat ini sudah ada kebutuhan untuk memanfaatan TIK dalam SIK (eHealth) agar dapat meningkatkan pengelolan dan penyelenggaraan pembagunan kesehatan. Sistem Informasi Kesehatan dilaksanakan oleh berbagai program dengan baik di lingkungan Kementrian Kesehatan maupun diluar sektor kesehatan. SIK dapat menyediakan data/informasi yang handa, memperbaiki permasalahan-permasalahan SIK dan mencapai target Renstra tersebut, maka perlu disusun suatu rencana Aksi Penguatan atau Roadmap SIK yang komprehensif dengan

Received: 29 October 2020, Accepted : October 2020 - Jurnal Photon Vol.11 No.1

DOI : https://doi.org/10.37859/jp.v11i1.2237

PHOTON is licensed under a Creative Commons Attribution-ShareAlike 4.0 International License 
mengintegrasikan upaya-upaya pengembangan dan penguatan SIK, yang melibatkan semua pemangku kepentingan terkait (KemenKes RI 2012).

Penyelenggaraan Sistem Informasi Kesehatan dilakukan oleh berbagai program, baik di lingkungan Kementerian Kesehatan maupun diluar sektor kesehatan. Dalam Rencana Strategis (Renstra) Kementerian Kesehatan tahun 2010-2014, terdapat target strategis untuk meningkatkan pengembangan Sistem Informasi Kesehatan. Agar SIK dapat menyediakan data/informasi yang handal, memperbaiki permasalahan-permasalahan SIK dan mencapai target Renstra tersebut, maka perlu disusun suatu Rencana Aksi Penguatan atau Roadmap SIK yang komprehensif dengan mengintegrasikan upaya-upaya pengembangan dan penguatan SIK, yang melibatkan semua pemangku kepentingan terkait. Merupakan sistem informasi kesehatan yang dikelola oleh dinas kesehatan baik kabupaten/kota dan provinsi. Laporan yang masuk ke dinas kesehatan kabupaten/kota dari semua fasilitas kesehatan (kecuali milik Pemerintah Provinsi dan Pemerintah Pusat) dapat berupa laporan, softcopydan laporan hardcopy. Laporan hardcopy dientri ke dalam aplikasi SIKDA generik. Laporan softcopy diimpor ke dalam aplikasi SIKDA Generik, selanjutnya semua bentuk laporan diunggah ke Bank Data Kesehatan Nasional. Dinas kesehatan provinsi melakukan hal yang sama dengan dinas kesehatan kabupaten/kota untuk laporan dari fasilitas kesehatan milik provinsi. Bank Data Kesehatan Nasional selanjutnya akan mencakup semua data kesehatan dari sumber data (fasilitas kesehatan), oleh karena itu unit-unit program tidak perlu lagi melakukan pengumpulan data langsung ke sumber data. Data kesehatan yang sudah diterima di Bank Data Kesehatan Nasional dapat dimanfaatkan oleh semua unit-unit program di Kementerian Kesehatan dan UPT-nya serta dinas kesehatan dan UPTP nya.

Dalam pelaksanaan nya puskesmas di Indonesia sudah menganut sistem informasi kesehatan yang di rancang pemerintah. Sistem informasi kesehatan yang dianut puskesmas pada saat ini masih di dominasi oleh SP2TP. Seperti diketahui bahwa puskesmas adalah ujung tombak pemerintah dalam upaya pelayanan kesehatan di masyarakat. Sesuai dengan KEPMENKES RI No 128 tahun 2004 tentang kebijakan dasar pusat kesehatan masyarakat bahwa puskesmas di definisikan sebagai unit pelaksana teknis di kabupaten/kota yang bertanggung jawab melaksanakan pembangunan kesehatan di suatu wilayah. Proses penyelenggaraan, pemantauan serta penilaian yang dilakukan Puskesmas terhadap rencana kegiatan yang telah ditetapkan baik rencan upaya wajib maupun pengembangan dalam mengatasi masalah kesehatan yang ada di wilayahnya. Salah satu bentuk pemantauan adalah dengan Sistem Informasi Manajemen Puskesmas (SIMPUS). SIMPUS merupakan pilihan bagi daerah dalam pengembangan sistem informasi kesehatan yang lebih cepat dan akurat. Pada potensi yang dimilikinya sebenarnya SIMPUS dapat menggantikan sistem pencatatan dan pelaporan terpadu puskesmas (SP2TP). Karena SIMPUS meru pakan hasil dari pengolahan berbagai sumber informasi seperti SP2TP, survei lapangan, laporan lintas sector, dan

Received: 29 October 2020, Accepted : October 2020 - Jurnal Photon Vol.11 No.1 DOI : https://doi.org/10.37859/jp.v11i1.2237 
laporan sarana kesehatan swasta. Seiring kemajuan tekhnologi. SIMPUS dikembangkan melalui sistem komputerisasi dalam suatu software yang bekerja dalam sebuah sistem operasi. Tetapi kendalanya SIMPUS masih belum berjalan secara optimal di daerah.

Pelaksanaan Sistem Informasi Kesehatan (SIK) di Indonesia tidak berjalan secara optimal dan belum maksimal dalam memberikan informasi yang di perlukan dalam proses pengambilan keputusan di berbagai tinkat sistem kesehatan. Puskesmas sebagai pelaksana kesehatan terendah mengalami kesulitan dalam melakuan pelaporan, dimana data antara satu laporan dari satu program dengan laporan lain dari program lainnya memiliki databes yang hampir sama. Di sisi lain aplikasi untuk membuat berbagai laporan tersebut berbeda-beda sehingga menimbulkan tumbang tindih dalam pekerjaan, maka dibutuhkan suatu Sistem Informasi Kesehatan untuk digunakan di daerah (Puskesmas dan Dinas Kesehatan) yang disebut Sistem Informasi Kesehatan Daerah (SIKDA) Generik.

Pengembangan aplikasi SIKDA Generik dikarenakan minimnya informasi persebaran penyakit dan info kesehatan yang tersebar di masyarakat akibat para petugas kesehatan sulit untuk mengidentifikasi secara cepat untuk itu perlu adanya penunjang yang memadai dalam setiap kegiatan pelayanan kesehatan. Dinkes Riau menyadari bahwa persoalan kesehatan membutuhkan teknologi untuk memudahkan pantauan kondisi kesehatah masyarakat yang menyeluruh mulai wilayah kabupaten/kota hingga desa, aplikasi berbasis data base tersebut memudahkan untuk memanatau segala ragam penyakit yang menjangkit disuatu daerah. Selain itu aplikasi SIKDA Generik diracang dan dibuat untuk memudkan petugas puskesmas saat melakukan pelaporan keberbagai program lingkungan Kementrian Kesehatan, Puskesmas langsat adalah salah satu puskesmas yang menjalankan SIKDA puskesmas yang ada di Dinas kesehatan Kota Pekanbaru. Terletak di Jl langsat No.13 Kelurahan jadirejo Kecamatan Sukajadi Kota Pekanbaru yang wilayah kerjanya terdiri dari 3 kelurahan yaitu : Kelurahan Jadirejo, Kelurahan Kampung Tengah, Kelurahan Kampung Melayu

Tabel 1. Data Ketenagaan Puskesmas Langsat Berdasarkan Pendidikan SDM di Unit Rekam Medis

\begin{tabular}{lll}
\hline No & Jabatan & Pendidikan \\
\hline 1 & Kepala Puskesmas Langsat & Dokter Gigi \\
\hline 2 & Kepala Unit Rekam Medis & $\begin{array}{l}\text { Sarjana Kesehatan } \\
\text { Masyarakat }\end{array}$ \\
\hline 3 & Penanggung Jawab SIKDA Generik & D3 Farmasi \\
\hline 4 & $\begin{array}{l}\text { Operator 1 SIKDA Puskesmas } \\
\text { Langsat }\end{array}$ & Sekolah Menengah Atas \\
\hline
\end{tabular}

Sumber : Puskesmas langsat Kota Pekanbaru Tahun 2020

Menurut Peraturan Pemerintah Republik Indonesia No 46 tahun 2014, dalam pasal 51 ayat 2 menjelaskan tentang Sumber Daya Manusia yang mengelola Sistem Informasi Kesehatan harus memiliki kompetensi paling sedikit dibidang Statistic, Komputer, dan Epidemiologi. Sedangkan Sumber Daya Manusia di

Received: 29 October 2020, Accepted : October 2020 - Jurnal Photon Vol.11 No.1

DOI : https://doi.org/10.37859/jp.v11i1.2237

PHOTON is licensed under a Creative Commons Attribution-ShareAlike 4.0 International License 
Puskesmas Langsat yang melakukan SIKDA Generik di Unit Rekam Medis berpendidikan yaitu Sarjana Kesehatan Masyarakat, Sarjana Kesehatan Masyarakat, Sekolah Menengah Atas. Ini menjadi permasalahan mengenai standar pendidikan Minimal.

Berdasarkan yang diperoleh informasi dari penanggung jawab pelaksanaan SIKDA Generik di Unit Rekam Medis di Puskesmas langsat bahwa Sumber Daya Manusia berpendidikan Sarjana Kesehatan Masyarkat, D3 Farmasi, Sekolah Menegah Atas. seharunya memiliki Kompetensi paling sedikit dibidang statistik, komputer, jaringan internet, listrik, dan ruang kerja. belum efektif. Dan tidak adanya tamatan Rekam Medis Perlu untuk dievaluasi guna untuk mengetahui apakah SIKDA Generik telah beroperasi sesuai pelaksanaannya. Agar tidak ada lagi kendala teknis di lapangan untuk melaksanakan pelaksanaan SIKDA Generik di Unit Reka Medis di Puskesmas Langsat di temukan bahwa SIKDA Generik baru berjalan di tahun 2017, dan tidak ada pelatihan atau bimbingan terkait aplikasi menyebabkan pengetahuan SDM terhadap aplikasi SIKDA Generik kurang. Dalam menghadapi SIKDA Generik puskesmas harus bisa mempersiapkan Sumber Daya Manusia Kesehatan seperti tenaga IT (informasi teknologi) yang sangat diperlukan dalam pelaksanaan SIKDA Generik dan juga pelatihan ataupun pengetahuan tentang sistem kerja SIKDA Generik untuk saat ini belum ada masih minimnya faktor pendukung untuk mengolah data rekam medis dan pelaksanaan SIKDA dalam penggolahan dan pengoperasian aplikasi online tersebut.

Sarana dan Prasarana dalam mendukung proses pelaksanaannya masih kurang memadai perlunya dukungan computer jaringan internet, listrik dan ruang kerja. salah satu kendala adalah dalam sarana dan prasarana terlihat dari jaringan pendukung untuk internet apabila mati lampu atau komputer error mengakibatkan penomoran tidak berurutan dikarenakan jaringan yang kadang error di akibatkan mati lampu atau gangguan pada jaringan, seharunya diperlukan internet dengan kapasitas besar sehingga jaringan pendukung aplikasi ini tidak ada hambataan lagi dan di perlukan mesin pembangkit listrik/genset.

\section{The Methods}

Jenis penelitian yang dilakukan adalah untuk mengetahui tentang Sdm, Sarana Prasarana, dan Dana. Metode yang digunakan dalam penelitian ini adalah deskriptif kualitatif dengan melakukan wawancara mendalam mendapatkan data yang mendalam sesuwai dengan fakta terlihat bersifat apa adanya yang bertujuan untuk mengetahui Analisis Sistem Informasi Kesehatan Daerah SIKDA Generik di Puskesmas langsat Tahun 2020. Penelitian ini sudah di lakukan di Puskesmas Langsat Kota Pekanbaru tahun 2020. Waktu penelitian ini dilakukan pada bulan Agustus- September 2020. Informan penelitian ini terdiri dari 4 orang,yang berhubungan langsung dengan persiapan SIKDA Generik, informan penelitiannya tergambar di tabel 2 berikut :

Received: 29 October 2020, Accepted : October 2020 - Jurnal Photon Vol.11 No.1 DOI : https://doi.org/10.37859/jp.v11i1.2237 
http://ejurnal.umri.ac.id/index.php/photon

Tabel 2. Subjek penelitian

\begin{tabular}{llll}
\hline No & \multicolumn{1}{c}{ Informan } & \multicolumn{1}{c}{ Keterangan } & Jumlah \\
\hline 1 & Informan utama 1 & Penanggun jawab SIKDA Generik & 1 Orang \\
\hline 2 & Informan Utama 2 & Kepala Puskesmas Langsat & 1 Orang \\
\hline 3 & Informan pendukung 1 & Kepala Unit Rekam Medis & 1 Orang \\
\hline 4 & Informan pendukung 2 & Operator Sikda & 1 Orang \\
\hline \multicolumn{2}{l}{ Sumber : Puskesmas langsat Kota Pekanbaru Tahun 2019 }
\end{tabular}

\section{Results and Discussion}

Sumber Daya Manusia (SDM) mengenai Sumber Daya Manusia di unit rekam medis puskesmas langsat terdapat 4 orang, 1 orang penanggung jawab sikda, 1 orang kepala puskesmas dan 1 orang lagi kepala unit rekam medis, 1 orang operator sikda, Yang dilakukan peneliti kepada semua informan peneliti berjumlah 4 (empat) orang dengan tamatan berbeda-beda yaitu 1 orang tamatan kedokteran gigi, 1 orang tamatan D3 farmasi, 1 orang tamatan S1 kesehatan masyarakat, 1 orang tamatan Sekolah Menengah Atas informasi yang didapat Sumber Daya Manusia belum ada untuk tamatan rekam medis sendiri. Sarana dan Prasarana dapat diketahui bahwa sarana dan prasarana Di unit rekam medis puskesmas langsat sudah mencukupi hasil wawancara tentang sarana dan prasarana. Dana dapat diketahui bahwa ketersedian dana puskesmas langsat sudah mencukupi.

Discussion

\section{Sumber Daya Manusia}

Menurut peraturan pemerintah Republik Indonesia No. 46 tahun 2014, dalam pasal 51 ayat 2 menjelskan tentang sumber Daya Manusia yang mengelola Sistem Informasi Kesehatan harus memiliki Kompetensi paling sedikit dibidang Statistik, Komputer, dan Epidemiologi.

Sedangkan Sumber Daya Manusia di puskesmas langsat yang melaksanakan SIKDA Generik di Unit Rekam Medis berpendidikan yaitu DIII farmasi, S1 Sarjana Kesehatan Masyarakat, Sekolah Menengah Atas ini menjadi permasalahan mengenai Standar Pendidikan Minimal.

Berdasarkan analisa peneliti tentang Sumber Daya Manusia bahwa SDM yang ada di puskesmas langsat degan petugas SIKDA berjumlah 2 orang sudah memenuhi kebutuhan dalam pengoperasian aplikasi SIKDA, akan tetapi masih didapatkan kendala-kendala dalam pengoperasiaan aplikasi SIKDA seperti Soft Ware dan Hard Ware yang susah dibuka dan lambat sehingga membuat keterlambatan pelayanan yang akan di berika dan apabila terjadi gangguan jaringan yang kadang hilang dan listrik kadang padam sehingga menghambat pelaksanaan SIKDA Generik.

\section{Sarana dan Prasarana}

Berdasarkan hasil analisa peneliti tentang Sarana dan Prasarana dalam menunjang pengoperasian aplikasi SIKDA sudah berjalan dengan baik akan tetapi masih terdapat kendala-kendala seperti

Received: 29 October 2020, Accepted : October 2020 - Jurnal Photon Vol.11 No.1

DOI : https://doi.org/10.37859/jp.v11i1.2237

PHOTON is licensed under a Creative Commons Attribution-ShareAlike 4.0 International License 
gangguan pada jaringan internet disamping itu adanya terjadi pemadaman lisrik diwilayah puskesmas langsat sehingga meghambat kinerja petugs dalam pengoperasian aplikasi SIKDA. Oleh karena itu sebaik pihak puskesmas tidak terfokus pada pengoperasian dengan mengunakan komputer, tetapi bisa dilakukan dengan menggunakan nonelektronik. Disamping itu pihak puskesmas juga sebaiknya memiliki fasilitas penujajng seperti ganset. Sebaiknya pihak Puskemas apa bila terjadi mati lampu pihak puskesmas bisa menggunakan nonelektronik, mencari alternatif penyediaan fasilitas penujang seperti Genset, Membuat ruangan kerja kusus untuk SIKDA biar tidak bergabung dengan loket.

\section{Alokasi Dana}

Penelitian yang di lakukan oleh jashinta logio (2016) mengatakan bahwa menujukkan bahwa pendanaan SIK sanga terbatas, di puskesmas tidak ada alokasi dana khusus untuk penyelengaraan SIK meggunakan dana bantuan operasional kesehatan (BOK).

Menurut peraturan Mentri Kesehatan Republik Indonesia nomor 97 Tahun 2015 Kemampuan pendapat daerah bervariasi dalam memperkuat sistem informasi kesehatan di daerah berdampak pula pada keberhasilan penguatan sistem informasi kesehatan secara berdampak pula pada keberhasilan penguatan sistem informasi kesehatan secara keseluruhan.

Berdasarkan pembahasan diatas menurut analisa peneliti bahwa puskesmas menyediakan alokasi tersendiri dalam pelaksanaan pengelolahan aplikasi SIKDA.

\section{Conclusion}

\section{Sumber Daya Manusia}

Sumber Daya Manusia yang ada di Unit Rekam Medis Puskesmas Langsat berjumblah 3 (tiga) orang, yang terdiri dari Sumber Daya Manusia di unit rekam medis puskesmas langsat terdapat 4 orang yang inti penanggung jawab SIKDA ada 3 orang, 1 orang penanggung jawab sikda 1 orang kepala unit rekam medis dan 1 orang lagi operator, jenjang pendidikan (S1 Kesmas, Dokter Gigi, DIII Farmasi, Sekolah menengah atas), Hanya penanggung jawab SIKDA yang mengikuti pelatihan SIKDA di tahun 2017 dan operator tidak mengikuti pelatihan. Ada melakukan evaluasi

\section{Sarana dan prasarana}

Sarana dan Prasarana di Puskesmas Langsat didapatkan bahwa Sarana yang ada sudah mendukung dalam pengoperasiaan aplikasi SIKDA seperti (Komputer, Wifi, Ruang Kerja). Adapun kendala yang didapat dari hasil wawancara mendalam terjadinya gangguan seperti Soft Ware dan Hard Ware yang susah dibuka dan lambat sehingga membuat keterlambatan pelayanan yang akan di berika dan apabila terjadi gangguan jaringan yang kadang hilang dan listrik kadang padam sehingga menghambat pelaksanaan SIKDA Generik

Received: 29 October 2020, Accepted : October 2020 - Jurnal Photon Vol.11 No.1

DOI : https://doi.org/10.37859/jp.v11i1.2237

PHOTON is licensed under a Creative Commons Attribution-ShareAlike 4.0 International License 


\section{Alokasi Dana}

Bahwa Alokasi dana tidak ada anggaran kusus yang disediakan untuk pelaksanaan aplikasi SIKDA karena sudah dialokasikan oleh Dinas Kesehatan. Anggaran alokasi dana di adakan jika di butuhkan saja, dan puskesmas biasanya hanya mengajukan kebutuhan dalam pelaksanaan aplikasi SIKDA.

\section{Acknowledgement}

Ucapan Terimakasih yang pertama kepada Allah SWT, Orang Tua, Dosen dan Pihak Puskesmas yang membantu peneliti menyelesaikan penelitian ini. Dan juga memberikan support kepada peneliti untuk kedepannya.

\section{References}

Asih Prasetyo Wati. (2016). Analisis Integrasi Sistem Informasi Manajemen Puskesmas Dan Sikda Generik Dengan Metode Prism

Dewi,Ratna Sari (2016). Diskes Riau Pantau Masyarakat Melalui SIKDA Generik. hhttp://m.goriau.com/berita/baca/diskes-riau-pantau-masyarakat-melalui-sikda-generik.html.

Dwi Santy Damayanti, dkk. (2015). Gambaran Penerapan Sistem Informasi Manajemen Kesehatan Berbasis WEB di Puskesmas Kota Makasar. Jurnal 2015.

Endah Sri Lestari, dkk. Evaluasi Sistem Informasi Kesehatan Di Provinsi Jawa Tengah Dalam Rangka Penguatan Sistem Informasi Kesehatan Nasional.

Fakultas Kesehatan Masyarakat,Universitas Diponegoro, (2016) Semarang Jurnal Manajemen Kesehatan Indonesia Volume 4 No 3 Desember 2016.

Erwin Susetyoaji, SKM, M.Kes. (2011) Sistem Informasi Kesehatan Daerah (SIKDA) Kabupaten Puwerejo. Dinas Kesehatan Kabupaten Puwerejo 2011.

Gavinov, dkk.(2016). Sistem Informasi Kesehatan. Yogyakarta : Nuha Medikal.

Hakam.f. (2016). Analisi, Perencanaan dan Evaluasi Sistem Informasi Kesehatan. Yogyakarta: Gosyen Publishing.

Isnawati Implementasi Apllikasi Sistem Informasi Kesehatan Daerah Sikda Generik Di UPT Puskesmas Gabungan Kabupaten Banjar (2016).

Khairina Isnawati, dkk. Implementasi Aplikasi Sistem Informasi Kesehatan Daerah (SIKDA) Generik Di UPT Puskesmas Gambut Kabupaten Banjar. Journal of information Systems for Public Health, Vol. 11, No.1, April 2016.

M.Mabrur Analisa Kualitas Layanan Sikda Terhadap Kepuasan Pengguna Dengan Metode Servqual Dinas Kesehatan Kabupaten Kampar.

Peraturan Mentri Kesehatan No. 75. (2014). Pusat Kesehatan Masyarakat.

Peraturan Mentri Kesehatan No. 97. (2015). Peta Jalan SIK Tahun 2015-2019

Peraturan Mentri Kesehatan Republik Indonesia No.92. (2014) Penyelenggaraan Komunikasi Data Dalam Sistem Informasi Kesehatan Terintegrasi

Received: 29 October 2020, Accepted : October 2020 - Jurnal Photon Vol.11 No.1

DOI : https://doi.org/10.37859/jp.v11i1.2237

PHOTON is licensed under a Creative Commons Attribution-ShareAlike 4.0 International License 